\title{
Escrever na paisagem Em italiano
}

\section{Sebastiana Fadda}

1. Título: Radical Changed Daphne_You must be my tree lo. Criação: Maria Federica Maestri e Francesco Pititto. Dramaturgia e imagoturgia: Francesco Pititto. Instalação, ambiente, objectos cénicos, som, encenação: Maria Federica Maestri. Música: Andrea Azzali. Performers: Valentina Barberini (Daphne) e Sandra Soncini (lo). Produção: Lenz Rifrazioni. Local e data de apresentação: Palácio D. Manuel, Évora, 7 de Julho de 2011.

2. Titulo: T.E.L. Conceito: Luigi De Angelis e Chiara Lagani. Dramaturgia: Chiara Lagani. Encenação, cenografia e luz: Luigi De Angeli. Música: Marco Baliani. Sonoplastia e sistemas interactivos: Damiano Meacci / Francesco Casciaro (Tempo Reale). Consultores artísticos: Tahar Lamri e Rodolfo Sacchettini. Cenografia, projecto técnico e operação: Nicola Fagnani (Ardis Lab). Performers: Marco Cavalcoli e Chiara Lagani. Produção: Fanny \&t Alexander. Local e data de apresentação: Teatro Garcia de Resende, Évora, 15 de Julho de 2011

3. Titulo: Con la virtù come guida e la fortuna per compagna. Conceito: Simone Derai, Moreno Callegari e Marco Menegoni. Texto, cena, luz, vídeo, figurinos e encenação: Simone Derai. Músicas: Marco Menegoni. Canto e voz: Paola Dallan e Emanuela Guizzon. Performers: Pierantonio Bragagnolo, Roberto Berti, Moreno Callegari, Marco Menegoni e Anna Branagnolo. Produção: Anagoor. Local e data de apresentação: Igreja de S. Vicente, Évora, 16 de Julho de 2011.

4. Titulo: Let the Sunshine in (Antigone) contest \# 1. Conceito e encenação: Enrico Casagrande e Daniela Nicolò. Direcção técnica: Valeria Foti. Performers: Silvia Calderoni e Benno Steinegger Produção: Motus. Local e data de apresentação: Rossio de São Brás, Évora, 20 de Julho de 2011.

Desde os primórdios da história do teatro nacional os palcos portugueses têm reservado generoso acolhimento ao teatro italiano e em italiano, no sentido mais lato do termo. Recordem-se: as inovações arquitectónicas e cénicas segundo Sebastiano Serlio e Leone De' Sommi (Ferreira 2004); a presença dos Comici dell'Arte do século XVI ao século XVIII'; os libretos para ópera de Pietro Metastasio e as comédias realistas do advogado veneziano Carlo Goldoni (Almeida 2007) no século das luzes; a persistência da melomania italiana apesar da invasão do (melo)drama romântico francês, a passagem de aclamados intérpretes de fama internacional - como Ernesto Rossi, Ermete Novelli, Eleonora Duse e Ermete Zacconi -, no século XIX; o fervor pelas novas vanguardas de que Filippo Tommaso Marinetti ${ }^{2}$ foi um dos portavozes e as ambivalências perante o teatro de Luigi Pirandello, no início e meados do século XX; os muitos e variados rumos que nos últimos cem anos foram surgindo, desde o esteticismo elitista de Gabriele Dannunzio às narrações habitadas de Gianluigi Tosto, contando-se, no lapso de tempo que separa os dois, dramaturgias tão diversas como as de Luigi Chiarelli, Eduardo De Filippo, Dario Fo, Pierpaolo Pasolini, Luigi Lunari, Enzo Moscato e Rocco D'Onghia, entre muitos outros autores, sem esquecer os demais espectáculos em língua italiana trazidos por companhias consagradas, como por exemplo, na década de Vinte, a Compagnia Drammatica Italiana dirigida por Dario Niccodemi, ou, mais próximos dos nossos dias, o Teatro di Roma e o Piccolo Teatro di Milano ${ }^{3}$.

No que diz respeito ao teatro de texto, deve-se aos Artistas Unidos a inestimável e recente divulgação em Portugal de novos e jovens autores - Antonio Tarantino, Spiro Scimone, Ascanio Celestini, Davide Enia, Fausto Paravidino e Letizia Russo -, incluindo-os no seu ambicioso projecto "Teatros que vêm de Itália", dedicando-Ihes um número especial da sua Revista, bem como uma série de
Estudada, documentada e com projecto de investigação exaustiva em curso por Maria João Almeida, investigadora e directora do Centro de Estudos de Teatro da Faculdade de Letras da Universidade de Lisboa, especialista do teatro goldoniano e da sua fortuna em Portugal no século XVIII.

20 Arquivo da Fundação Mário Soares regista que, em 1932, decorreu uma "Sessão pública em Lisboa com o futurista italiano Marinetti. / Marinetti poeta conotado com Mussolini, encontra-se em Lisboa para uma sessão pública onde se sentarà entre António Ferro e Júlio Dantas. Almada Negreiros protesta e Álvaro de Campos escreve "Marinetti Académicon" (<http://www.fmsoares $\mathrm{pt} / \mathrm{aeb} / \mathrm{crono} / \mathrm{id}$ ? id $=035427>$; data de acesso: 08/10/2011).

${ }^{3}$ Para informações mais completas, cf. o sitio <www.fl.ul.pt/CETbase/ default.htm>. 
Radical Chan

Daphne_You must be my tree 10

de Maria Federica Maestri

e Francesco Pititto

enc. e instalação,

Maria Federica Maestri,

Lenz Rifrazioni,

Parma, 2008

(Sandra Soncini [lo])

fot. Francesco Pititto.

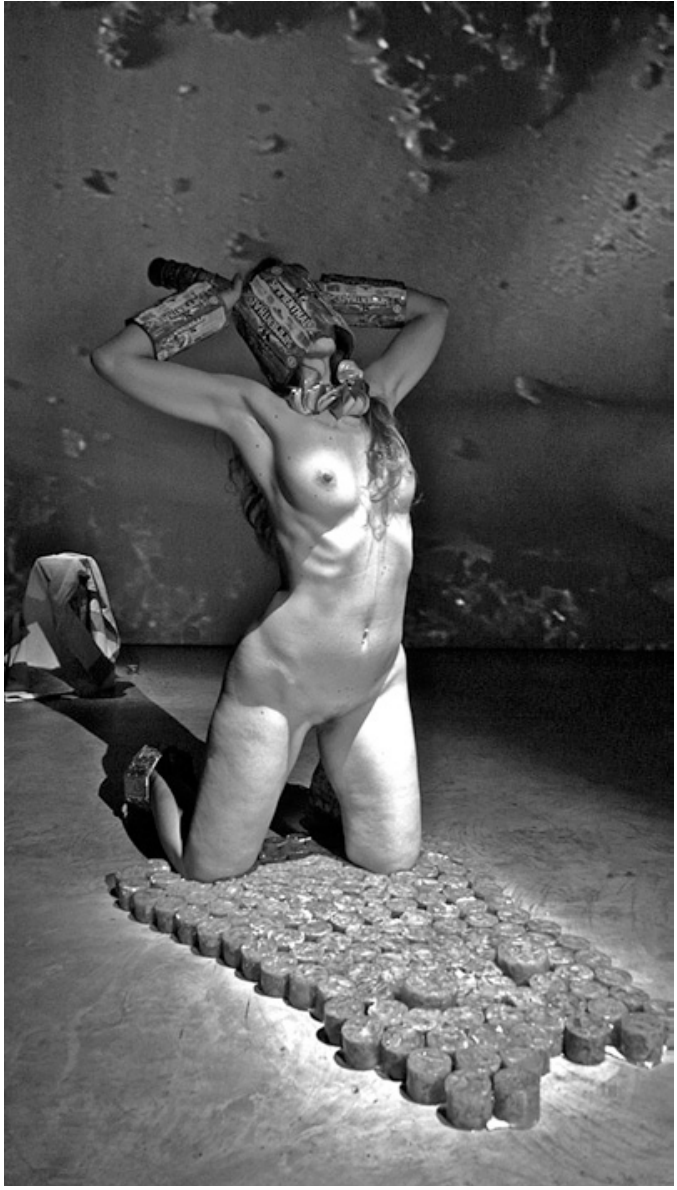

espectáculos, leituras públicas e encontros, em italiano em português, alguns integrados na XXI edição do Festival Internacional de Teatro de Almada de 2004 e outros posteriores, por vezes na presença ou com interpretação dos dramaturgos, havendo continuidade e registo também na já respeitável lista de traduções editadas na colecção Livrinhos de Teatro, em parceria com os Livros Cotovia. Jorge Silva Melo e os Artistas Unidos bem entenderam que não há uma Itália, mas muitas, distantes e diferentes entre si, por vezes unidas pelo teatro, pelas efabulações cénicas que falam de terras, gentes, tempos e realidades longinquas, por vezes comungando a mesma História, ou a condição comum de exclusão dela, convocando-a, contrariando a tendência para o apagamento da memória e a descontextualização das configurações do presente.

No que diz respeito ao teatro de impacto visual e/ou escrita cénica menos convencionais, é no âmbito de eventos, espaços, circuitos, produções de grande ressonância e/ou capacidade financeira consistente que em geral, os portugueses puderam assistir a criações de Giorgio Barberio Corsetti (nos Encontros Acarte da Fundação Calouste Gulbenkian, Culturgest e Teatro Nacional S. João), António Latella (na Culturgest), Pippo Delbono (no Centro Cultural de Belém [tb. Festival Internacional de Teatro de Almada] e Museu de Serralves), Societas Raffaello Sanzio (no Edificio da Alfândega do Porto [PoNTI], Centro Cultural de Belém [Festival Europa e Alkantara Festival]), Emma Dante (nos Teatros Carlos Alberto, Municipal Rivoli e Centro Cultural de Belém) ${ }^{4}$. E nelas puderam perceber como se questionam e experimentam novos conceitos, entendimentos e estéticas contemporâneas, não raro resistentes e fragmentárias quando não residuais, de sofisticada beleza plástica e dissonante denúncia cívica, revelando como as fachadas glamourosas das realidades formatadas da sociedade consumista mal disfarçam o cinismo sinistro das ideologias

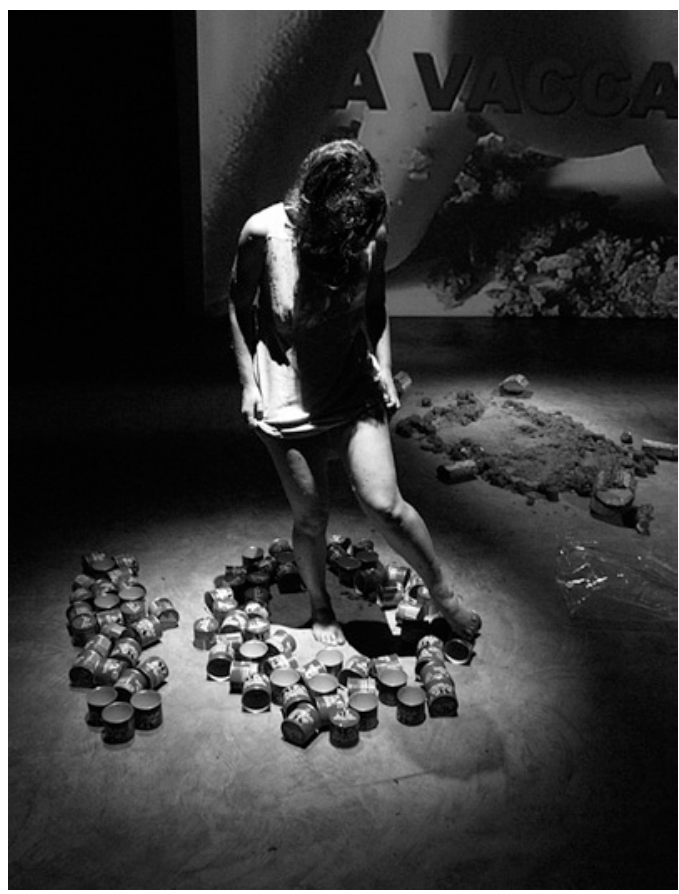

De discreta realização no Alentejo, mas de reconhecida projecção internacional, a Escrita na Paisagem - Festiva em geral, e especificamente as artes do espectáculo, assumidas como lugar de cruzamentos transdisciplinares. Apresentou este ano a sua oitava edição, naquele que é o seu electivo circuito descentralizado e alternativo, de Performance e Artes da Terra, vem acolhendo as artes 


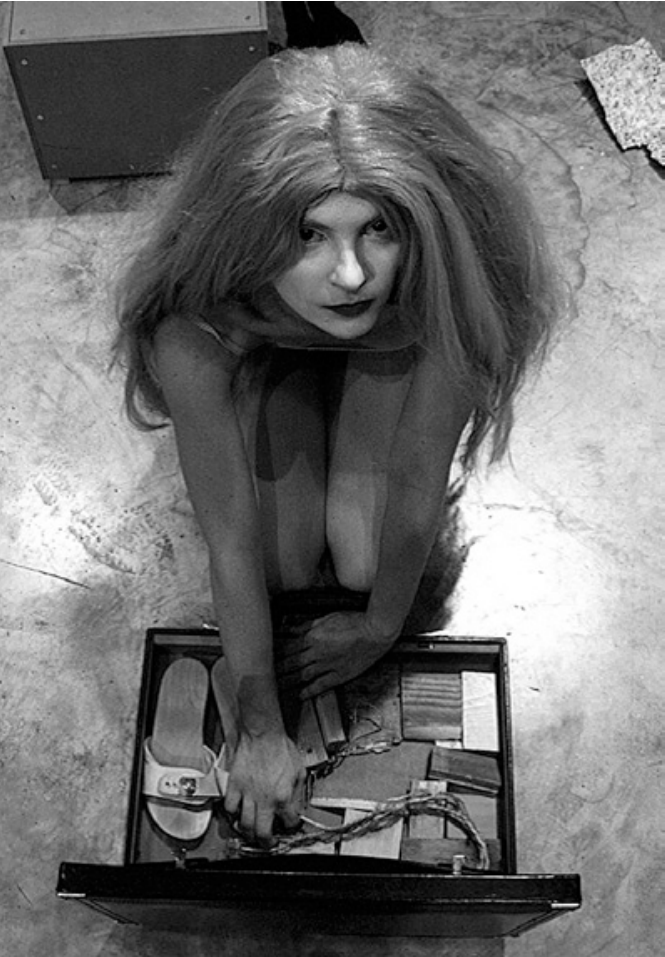

abrigando a importante resenha "Embaixada do Teatro Italiano em Portugal": celebração e montra das mais recentes tendências das artes cénicas italianas, apoiada com inteligente visão e sentido de oportunidade pelo Ministero per i Beni e le Attività Culturali e pelo Instituto Italiano de Cultura em Portugal, mas também por instituições portuguesas que valorizam a competência e obstinação do seu fundador e director artístico, José Alberto Ferreira, dedicado organizador e mentor desta "festa" integrada no Festival.

Importa salientar que o fio condutor deste ano propunha o tema do "mito", convidando artistas e espectadores a reflectirem sobre o lugar que ele ocupa no nosso tempo e sobre as modalidades da sua actualização e/ou sobrevivência. Dito por outras palavras, e glosando a proposta do director artístico, se na antiguidade clássica o mito cimentava a coesão da polis, nos dias de hoje, em que os governantes exibem a sua flagrante distância relativamente ao conceito de bem comum, que mitos são ainda possiveis? Numa realidade em constante transformação, e perante o divórcio entre a política e a cidade, é preciso questionar "mitos e mitologias que pontuam o mundo contemporâneo", mas também "mitificações e mistificações que as narrativas colectivas vão disseminando e inscrevendo em nós, revisitando mitos contemporâneos, seja numa dimensão histórica, seja estabelecendo aproximações à cultura mediática e cinematográfica dos séculos XX e XXI" (Ferreira 2011: 3). Logo, desafiando a atracção lusa pela inércia congénita, as Artes Performativas e da Terra propõem-se indagar sentidos, na dupla acepção de "significados" e "direcções".

Quanto aos "nove poderosos espectáculos, menos pautados pela palavra que pela construção de imagens fortes e deslumbrantes, explorando universos mitológicos vertidos nas linguagens e contextos da cultura contemporânea" (Ibid:: 6), foram trazidos por seis grupos e criadores de referência, que preencheram o seguinte

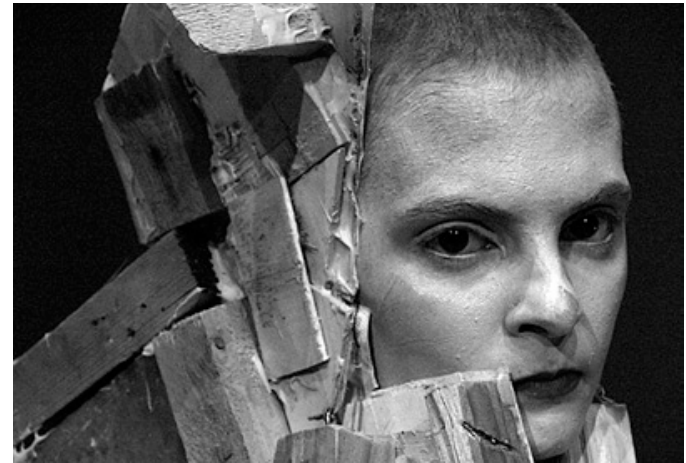

$<>$
$\mathrm{V}$

Radical Changed

Daphne_You must be my

treelo,

de Maria Federica Maestri

e Francesco Pititto,

enc. e instalação, Maria Federica Maestri, Lenz Rifrazioni, Parma, 2008 (Valentina Barberini [Daphne]),

calendário: Radical Changed Daphne_You must be my tree lo, por Lenz Rifrazioni, no dia 7 de Julho; T.E.L., por Fanny \& Alexander, dia 15 de Julho; Con la virtú come guida e la fortuna per compagna, por Anagoor, no dia 16 de Julho; Let the Sunshine In (Antigone) Contest\# 1, por Motus, nos dias 20 e 22 de Julho; $(a+b) 3$, por Muta Imago, nos dias 22 e 23 de Julho; Your Girl_Cowboys_Joseph, por Alessandro Sciarroni_C.C.00\#, de 27 a 30 de Setembro. A Sinais de cena pôde assistir a cinco deles, que serão comentados a seguir ${ }^{5}$. Sobre os remanescentes, a apresentação contida no programa anunciava a criação de Muta Imago como sendo uma "estória comovente do gesto de desenhar numa parede uma sombra. Do gesto de abraçar uma sombra. Entre o teatro e o cinema" (Ibid: 22), enquanto as de Alessandro Sciarrone proporcionariam "três espectáculos notáveis, marcados pela beleza e pelo poder da imagem" (Ibid.: 38). Aguardamos expectantes novas ocasiões para os (re)encontrarmos a todos.

\section{Lenz Rifrazioni: Radical Changed Daphne_You} must be my tree lo.

A origem da companhia Lenz Rifrazioni, sediada em Parma e fundada em 1985, deve ser procurada nas inquietações daquela geração que, nos anos Setenta e Oitenta, contribuia para a actualização do teatro italiano não convencional sob a designação genérica de Teatro de Pesquisa.

Caracteristicas a destacar, neste caso concreto, são a longa gestação e amplo fôlego dos projectos, com base em textos literários propriamente ditos e em textos dramáticos, de várias épocas, geografias e autores, como Shakespeare, Calderón de la Barca, Goethe, Dostoievski, Lorca e Genet, os Irmãos Grimm e Hans Christian Andersen, e que visavam a desconstrução dos originais para os reinventar e devolver através de uma escrita cénica baseada numa rigorosa transcrição visual. Sublinhe-se o empenhamento na formação, activada através do projecto "Pratiche di Teatro" (Práticas de Teatro), e na sensibilização, e envolvimento, de públicos especiais - constituídos por deficientes mentais -, perseguida através de iniciativas e laboratórios integrados reunidos sob a denominação de "Pratiche di Teatro Sociale" (Práticas de Teatro Social). Quanto à sua presença em Portugal, esteve ligada ao projecto Radical Change, que tem sido desenvolvido desde 2007 com a construção performativa em dez instalações das Metamorfoses de Ovídio, duas das quais foram apresentadas numa das salas do belo Palácio D. Manuel de Évora: Io, a mostrar a transformação daquela ninfa em novilha, amada por Zeus e por ele ocultada aos olhos e ciúmes de Hera sob o aspecto do animal; Daphne_You must be my tree, a acompanhar a transformação em loureiro de outra ninfa, que pretendia fot. Francesco Pititto.

${ }^{5}$ Agradece-se a gentil

colaboração das

companhias e dos

criadores, em especial

Maria Federica Maestri e Simone Derai, pelas imagens, informações e esclarecimentos fornecidos. 


$$
\begin{array}{r}
<> \\
v \\
\text { T.E.L., } \\
\text { de Luigi De Angelis } \\
\text { e Chiara Lagani, } \\
\text { enc. Luigi De Angelis, } \\
\text { Fanny \&t Alexander, } \\
\text { Nápoles / Turim, 2011 } \\
\text { (Chiara Lagani), } \\
\text { fot. Enrico Fedrigoli. }
\end{array}
$$
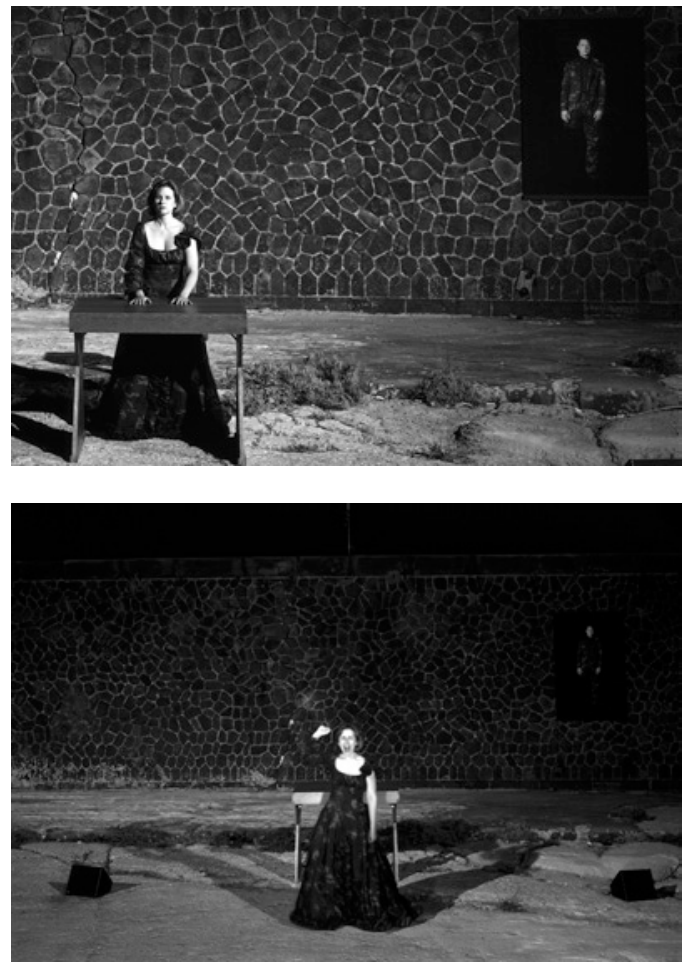

evitar o desejo de Apolo. Os resultados justificam e explicam o recurso não apenas à análise dramatúrgica, mas também a uma imagoturgia, que procede à tradução em imagens, conjugando as duas tarefas especificas para a finalidade de criar um roteiro espectacular que equaciona os aspectos espaciais, cinéticos, plásticos, sonoros e filmicos que substituem (quase) por completo as palavras. Surpreendente e inventiva, a metamorfose de 10 , com o corpo nu de Sandra Soncini duplamente exposto - em vídeo, por porções inspeccionadas pela objectiva da câmara, e ao vivo, por inteiro, em movimentos indicadores do total domínio de cada músculo -, em que o corpo de mulher se torna corpo de animal. A um primeiro - ou superficial - olhar, dir-seia que o corpo feminino se tornava carne de vaca enlatada transitando da "exaltação do corpo místico, corpo de beleza e êxtase" (Ferreira 2011: 15), para a sua reificação, corpo físico espezinhado em carne cozida e para consumo. Em cena, as muitas latas da histórica marca "Simmenthal", pareciam indícios da passagem dum sistema defensor do mito da beleza e do desejo para um sistema defensor de produtos industriais, para consumo em larga escala e gerador da mais-valia capitalista. Trivializando a leitura analítica, e citando um velho provérbio, não no sentido consagrado pelo uso mas no seu sentido literal, poder-seia dizer que na antiguidade os homens tinham mais olhos (a capacidade de contemplação do belo) que barriga (a necessidade de ingurgitar / acumular matéria), enquanto na contemporaneidade têm mais barriga que olhos. Prosseguindo nesta óptica, emblemática seria também a parte em que a performer primeiro se ajoelhava, e a seguir se deitava, no chão, por cima de um "leito" de carne préconfeccionada, acabando por lamber os dedos e as mãos, numa acção autofágica alusiva à tendência das sociedades actuais, capazes de se devorarem a si próprias. Marcante, a projecção da imagem final, com o rosto da mulher coberto pela gelatina alimentar que, a nivel referencial, reenviava para as possiveis lágrimas de desespero cristalizadas,

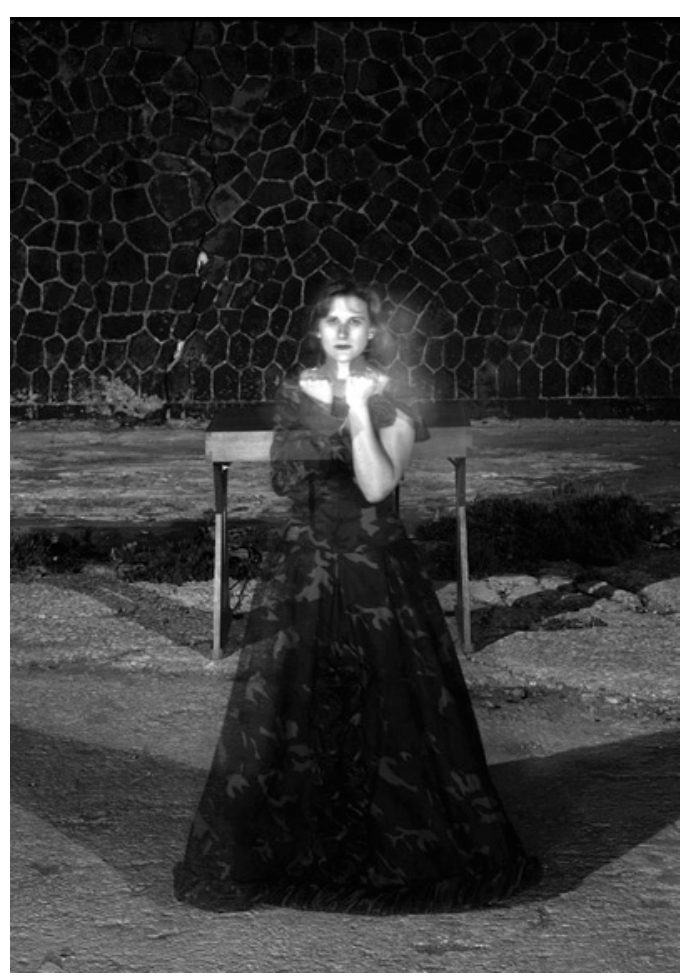

resultantes da posse consumada por violação. As palavras, reduzidas à sua existência isolada e gráfica, projectadas no vídeo, sugeriam tópicos da leitura dramatúrgica e núcleos de condensação semântica. Para demonstração da subjectividade do olhar, caso fosse necessário, refirase que esta interpretação redutora contraria as intenções, mais plásticas e artísticas, que nada têm a ver com a pop artamericana, dos criadores Maria Federica Maestri e Francesco Pititto, hábeis tecedores de diálogos entre tradição e contemporaneidade: a imagem inicial, com a performer dando as costas ao público, é uma citação directa duma pintura de Correggio inspirada no mito de lo, e que encontrou na beleza renascentista de Sandra Soncini um perfeito complemento; não havia desgaste nem banalização do mito na matéria, mas antes o oposto, ou seja, a vontade de transformar o quotidiano elevando-o, exaltando e enobrecendo a matéria, reconduzindo-a à sua dimensão mítica, devolvendo-Ihe uma identidade perdida; a gelatina das imagens finais era já carne madura que, ressequida pela perda do sangue (e do sangue menstrual), voltava à sua essência, etérea e vibrante. Os artistas vêem mais longe, mais alto e mais fundo do que o olhar comum. Eles conhecem outras gramáticas para preservar e reescrever os mitos, estabelecendo novas relações semânticas entre signos e significados, reconvertendo o quotidiano mais banal em poesia insuspeitável. Igual força imagética animava Daphne, que surgiu no acto de fuga do deus Apolo, vistosa, com peruca loira e botas de cano alto, lembrando uma boneca triste, mais jovem Lolita do que corpo virginal, enquanto o vídeo anunciava a futura árvore, mostrando as sementes da qual germinaria: dois amendoins enfiados no nariz, lembrando uns olhos felinos de pálpebras fechadas ou uns globos apagados numa vaga caveira, mas também, e sobretudo, elementos de oclusão, e prenúncio da futura dispensa, do aparato respiratório. Mais tarde, depois de extraídos duma mala pequenos paralelepípedos de madeira, Valentina Barbarini procederia à sua colocação por entre 


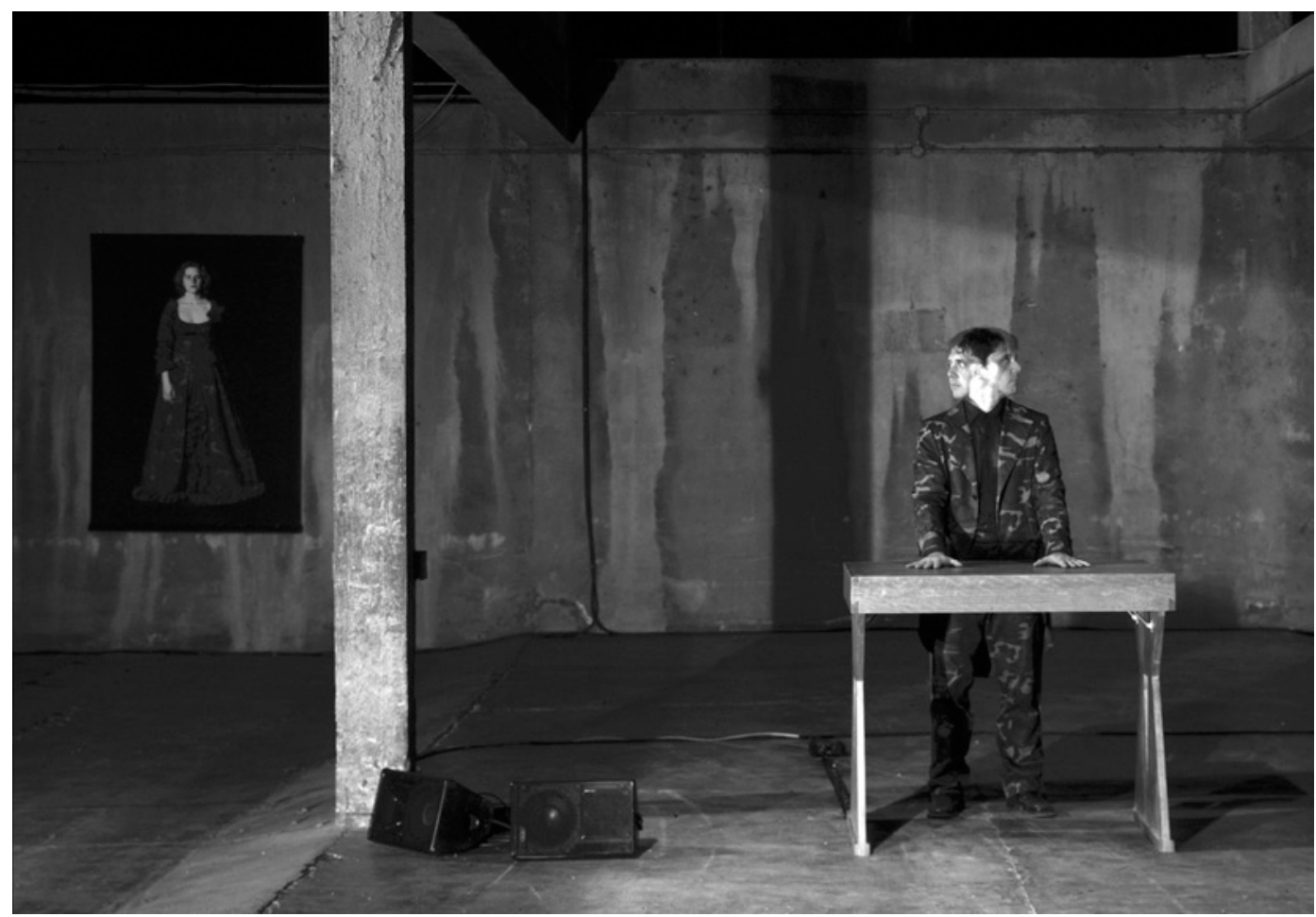

T.E.L.,

de Luigi De Angelis

e Chiara Lagani,

enc. Luigi De Angelis, Fanny \& Alexander,

Santarcangelo di

Romagna, 2011

(Marco Cavalcoli),

fot. Enrico Fedrigoli. os dedos das mãos, sugerindo os ramos, e retiraria a peruca, revelando a cabeça rapada, subtraindo um traço de feminilidade associada ao corpo enquanto objecto de desejo, para criar o futuro tronco de árvore, a partir da uniformidade com o tronco de ninfa, renunciando à antiga estrutura fisica. 0 processo de abandono do velho invólucro e a integração do novo continuava com várias outras acções: descalçar as botas, calçar socas e vestir, por cima destas, um par de meias da cor da pele, incorporando deste modo as socas, que talvez se tornassem raizes na sua fase inicial, ou, na intenção dos criadores, eram já uma insinuação da casca do vegetal. Só então era verbalizado o medo do amor (na origem, a rejeição com que Eros castigava a soberba de Apolo), pelo pedido de auxílio que a ninfa dirigia ao pai, gritando para um microfone. E a mudança acontecia, concretizada por uma silhueta repleta de pedacinhos de madeira, moldada a partir das especificidades do corpo da performer, por ela carregada, depois arrumada e largada por cima de um cubo, também de madeira, juntamente com as botas. No vídeo, entretanto, o vermelho do sangue tornava-se no verde da seiva. 0 fundo sonoro antes estridente fazia-se harmonioso. Daphne, como antes lo e seguindo um percurso paralelo, já estava desencarnada.

Do novo status de árvore bissexuada, o louro, havia indicação pelo corpo andrógino, feminino (pela presenças dos pequenos seios) e masculino (criado enfiando a camisola nos collants à altura do púbis, simulando o volume dum falo) ao mesmo tempo. Os gestos rígidos podiam finalmente soltar-se e fazer-se dança, numa expressão de quase felicidade, derivada da germinação em flores, materializada e transmitida no vídeo pela reprodução destas a partir daquele bocado de madeira onde tinham sido pousados os amendoins.

Mais uma vez, o quotidiano fazia-se poema. Em loe Dphne há um último aspecto comum que importa assinalar: a ausência dos deuses, co-protagonistas dos mitos, exilados da cena. Permanecia, na tradução inter-semiótica, o mistério das obras e das suas transmutações alquimicas.

\section{Fanny \&t Alexander: T.E.L.}

Fanny \& Alexander, companhia sediada em Ravenna e fundada em 1992, estreou-se em Portugal na edição de 2010 da Escrita na Paisagem, e tem vindo a afirmar-se como refinada inventora de dispositivos cénicos, narrativos, plásticos e sonoros de extraordinária eficácia e originalidade, de que há eloquente testemunho no livro bilingue 0/Z. Atlante di un viaggio / Atlas of a theatre journey (2010), intrigante diário de bordo de uma viagem em dez etapas, ou seja em dez espectáculos, inspirados no imaginário de Lyman Frank Baum. Dos espectáculos ao livro, da experiência efémera à fixação que a capta, outras viagens na viagem: pela articulação da linguagem enquanto texto, de verbal a escrito, e enquanto imagem, primeiro ao vivo e a seguir em flashes fotográficos; pelos roteiros dos colaboradores e das respectivas sensibilidades que, ao mesmo tempo que guiam os leitores na viagem observada, instigam-nos a enveredar por outras lógicas, a partir dos olhares e das pistas esboçadas e deixadas em suspenso ou traçadas pelos observadores. A este respeito, veja-se também o rico reservatório informativo e iconográfico disponivel no sítio internet $<$ www.fannyalexander.org/>. Quanto ao espectáculo trazido a Évora este ano, T.E.L., foi apresentado naquela pequena jóia da arquitectura neoclássica oitocentista que é o Teatro Garcia de Resende, com a sua sala à italiana de início ocultada aos espectadores, convidados a tomarem lugar no palco, o mínimo que se poderá dizer é que foi desafiante. "Palco" no palco, de início, um espaço quadrado delimitado por marcas brancas no chão e tendo como parede do fundo, provisória, o pano de boca fechado no proscénio. As cadeiras do público estavam colocadas à volta, nos três lados remanescentes, para que, catapultado na área de actuação tradicionalmente reservada ao actor, ele saisse da sua posição passiva, estimulando-se uma recepção mais activa, ou uma percepção mais afinada, através da proximidade com a equipa técnica, e com os 

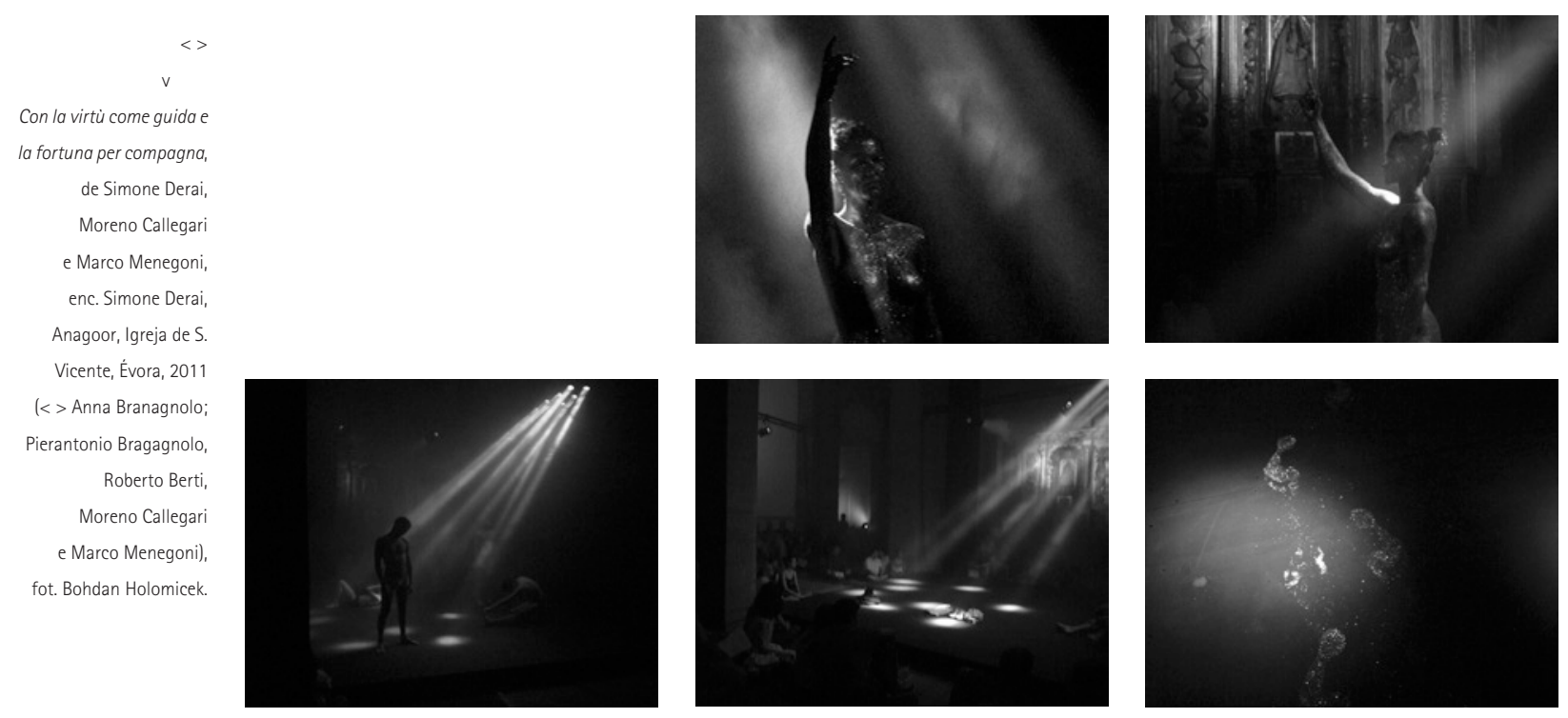

inusitados efeitos sonoros e rítmicos criados, bem como com os performers, que acompanhavam e interpretavam as músicas com extrema precisão. No centro ao fundo, uma mesa; na mesma linha horizontal, nas extremidades esquerda e direita, dois grandes altifalantes; nas linhas diagonais, a partir do centro da mesa, mais à frente, dois outros altifalantes. Primeiro surgiu Chiara Lagani - de traje elegante e comprido, padrão mimético, de auscultadores e microfone na cabeça -, que se posicionou por trás da mesa, e fazia deslizar a mão no tampo electrónico, produzindo sons que tanto poderiam ser de ondas, como de comboio em andamento; depois de uma breve interrupção, recomeçava o movimento em sentido contrário, aumentando a velocidade até atingir uma velocidade de cruzeiro. A viagem começou. Os reflectores incidiam na artista, que primeiro bebeu e depois, ao pousar o copo, provocou um som semelhante a uma explosão, repetindo o efeito várias vezes, o que causava ansiedade e corrida acelerada, assim dificultando o caminho. Acabada a corrida, abria-se o pano de boca, deixando a sala à vista. A performer colocava-se aquém da mesa, no meio do palco, dava início a movimentos como de aquecimento, e depois dançava, ao som de ritmos ofegantes, uma partitura de ordens, de tom imperioso e militarizantes, dadas por uma voz emitida (supunha-se) por uma silhueta humana visivel num dos camarotes mais centrais da primeira ordem: ele, general, manipulador ou eminência parda; ela, instrumento, marioneta ou bode expiatório. Os movimentos continuavam mesmo quando a voz se calava lembrando Charlie Chaplin em Tempos modernos, que em casa repetia os gestos mecânicos da cadeia de produção. Até o frenesim abrandar, parar, ela voltar atrás da mesa, dar-se a troca dos papéis, com ela a mandar e ele (supunhase) a obedecer, ou retornar aos papéis anteriores, ela a procurar algo ou alguém na plateia, para voltar ao palco e recomeçar a gesticular freneticamente, soltando mais fios narrativos e sugestões evocadoras de uma guerra e de uma conspiração, um rejubilar vitorioso e uma cidade libertada, o grotesco do orador de turno, a recomendação de desconfiar dos sonhos e dos sonhadores, a música electrónica em crescendo, sincronizada com - ou a orquestrar a - coreografia gestual, até se encerrar a primeira parte. Depois do intervalo, com o pano de boca fechado, surgiu Marco Cavalcoli, que também vestia um figurino mimético e repetia a sequência de gestos, movimentos, ordens e execução das ordens, permutas, vigilâncias e assim por diante, reiterando a sugestão de presumiveis cenários e estratégias de guerras, controlos, oposições, libertações (?). Que expressão atroz, "cenários espectáculo do poder, indiferente ao facto de que os mortos, no fim, não se levantam... Mas quem é "o outro"? Não somos todos "outros", aos olhos dos outros? E porquê quem manda esquece que também é, por sua vez, "o outro"? Se pudéssemos fazer o deserto na mente, para pensar... Se os poderes instituídos não desconfiassem dos sonhadores, porque podem recitar... Se vissemos todos, com olhos de ver, o horror da cena final, depois de o performer ter saído, quando duas crianças, duplicando nos figurinos a imagem dos adultos que os precederam, brincavam com os carrinhos, ambulâncias e helicópteros de guerra, reproduzindo os criminosos e macabros "jogos" dos governantes chamados a decidir e responder pelos destinos colectivos... Talvez tivéssemos outro mundo que não este. Talvez pudéssemos continuar a sonhar.

\section{Anagoor: Con la virtù come guida e la fortuna per compagna.}

Criada em 2000, a companhia véneta Anagoor tem uma formação ecléctica, cujo leque de interesses abrange áreas de conhecimento tão específicas e especializadas como, por exemplo, a filologia clássica e a musicologia, a história da arte, das artes decorativas e das artes visuais, experimentando sinteses produtivas com as artes plásticas, cénicas e performativas, criando ambientes sugestivos, sonoridades encantatórias, imagens de exigente depuração estética, quadros vivos portadores de memórias ancestrais. Neste sentido, a nave central da Igreja de São Vicente de Évora, espaço que acolheu Con la virtù come guida e la fortuna per compagna, foi o lugar ideal para tornar o espectáculo, uma performance site specific de curta duração mas de grande intensidade, numa cerimónia em que as reminiscências míticas e rituais, sagradas e profanas, litúrgicas e performativas, encontravam felizes ressonâncias e amplificavam as simbologias nelas inscritas. Os espectadores eram recebidos ao som martelante de um de guerra": a guerra cada vez mais entendida como 

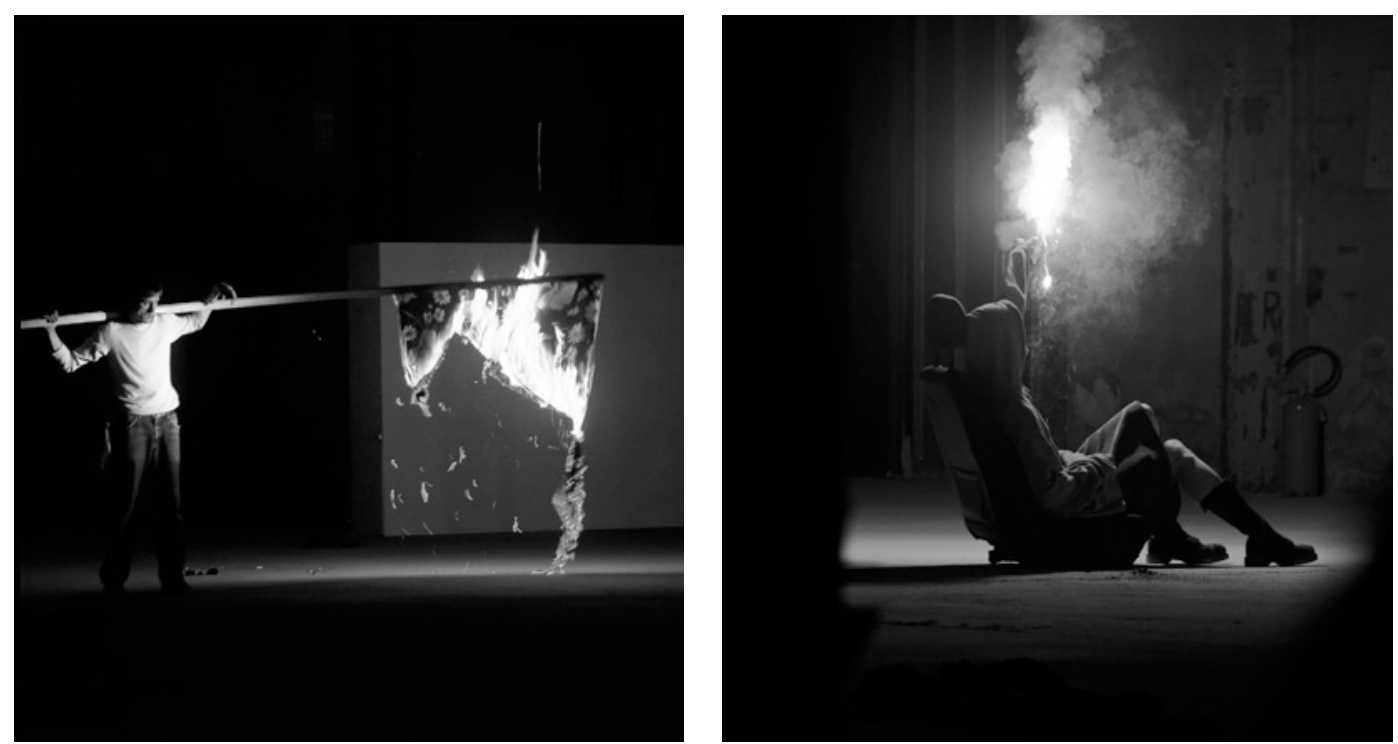

tambor e, na escuridão, cortavam o fumo brumoso e espesso dos óleos essenciais para poderem escolher o seu lugar. Quando o tambor parou, vozes melodiosas entoaram ao vivo um canto, e a voz off de um narrador aludia a um tempo sem tempo (antes da queda no pecado original ou da alienação no sistema produtivo...), em que "passear na terra era um prazer", citação do filme The Baby of Macon de Peter Greenaway. Tratava-se da paráfrase performativa dos momentos antecedentes e consecutivos à vestição do menino da película ${ }^{6}$. Os intérpretes traziam as suas próprias vestes, não de ouro, mas tão só um suéter, calças de ganga e ténis. Um estrado demarcava o limite de actuação dos performers, que, pousadas as roupas e em trajes menores, faziam o seu aquecimento, com exercicios de alongamento, descontracção e concentração, encerrando esta fase preparatória com abluções purificadoras, utilizando com parcimónia a água guardada em recipientes de vidro e um pano branco, para depois se vestirem, as camisolas com capuz sugerindo monges modernos e laicos, ou simplesmente os adolescentes de hoje, ainda e sempre à procura de identidade enquanto tentam esconder as suas inseguranças. Terão sido as virtudes louvadas no filme humildade, castidade, prudência, piedade, força e pobreza -, por sinal, ou paradoxo, comparadas a acessórios preciosos mas desvalorizadas pela quantificação do preço, transferidas nos figurinos dos jovens, ou antes numa mulher, que entrava no espaço cénico com o corpo inteiramente coberto de maquilhagem dourada? Ou terá sido o antigo Bezerro de Oiro pagão reconvertido em sacerdotisa e guia, talvez a Virtude do título, enquanto conceito em sentido lato, que todas as virtudes abrigaria, portadora também da Fortuna que protegeria os peregrinos que a ela se consagrassem? Como precisou o encenador, Simone Derai, o canto, a cappella, dispensou a amplificação devido à acústica perfeita do espaço; quanto ao tema central, estava "composto segundo o sistema gregoriano de escrita musical a partir dos próprios gestos da dança [que seguiria], mas misturado com temas da tradição musical veneziana do período bizantino ao período renascentista" (Derai 2011, tradução minha). 0 canto, ainda, acompanharia, ou estabeleceria, os ritmos e intensidades dos movimentos dos performers, juntamente com as orientações da deusa / guia, participando todos num momento de comunhão / dança ritual, feita por oficiantes a lembrar dervixes, com movimentos próximos do tai chi, em perfeita sincronia, antes lenta, depois em progressiva aceleração, como as respirações, que se sobrepunham ao canto, em crescendo até atingir o cume, e depois em desaceleração, com os corpos oscilantes, pararem. Terminada a função, os oficiantes regressariam para as trevas de que sairam. A mulher dourada, no meio do espaço de representação e de braço direito erguido, apontaria para o céu e desapareceria. As cantoras retirariam os objectos utilizados, recipientes e toalhas, e afastar-seiam. Sobrariam as luzes e o fumo brumoso, o silêncio e a força da matéria, a densidade dos sincretismos culturais e artísticos vivenciados, o rasto de transcendência deixado pela fisicalidade, o eco dos gestos e emoções, as memórias de épocas passadas e presentes, de terras distantes e familiares, pairando na atmosfera. Com la virtù come guida e la fortuna per compagna é uma das seis partes que compõem um projecto mais amplo, Fortuny, que celebra, reinventa e desmistifica uma cidade que, no seu apogeu, contém os sinais do declínio: no século XVII, ao realizar a Punta della dogana a mare, Veneza representa-se a si própria como um grande navio de proa virada para as águas e encimada por "um ídolo em precário equilibrio por cima de um globo de ouro, uma deusa apoiada num só pé e estendida para o mar (...) a Fortuna. Veneza está assim votada à sua potência para invocar ventos propícios numa época em que já está sensível a sua decadência" (Anagoor 2011, t.m.). Amplia-se então a rede de significados: sem o sabermos, mas de algum modo pressentindo sentidos indefiniveis, a nave da igreja de São Vicente foi, também e ainda, por uma noite, um navio veneziano guiado pela deusa Fortuna, largando no ar o pó dourado do fausto, porém brilhando como as estrelas, que continuam a luzir depois de terem desaparecido. $E_{\text {, }}$ sem conseguir ensombrar essa beleza fugidia, para norteio e precaução dos navegantes, o impalpável nevoeiro carregaria as promessas de tempestades em provir, anunciadas por aquele dedo indicador esticado em direç̧ão ao céu. Recomenda-se uma visita ao sítio internet da companhia - <www.anagoor.com $>-$, onde poderá acederse a documentos expressivos de um percurso original. metrónomos humanos que não perdiam o seu centro, até
$<>$

Let the Sunshine in (Antigone) contest \# 1, conceito e enc. Enrico Casagrande e Daniela Nicolò, Motus, Officine per le Grandi Riparazioni, Torino, 2009 (< Benno Steinegger; $>$ Silvia Calderoni), fot. Marcello Como.
${ }^{6}$ Cf. o sitio internet: <http://www.youtube com/watch?v=E8UfggsV uvw> (data de acesso: 17 de Outubro de 2011). 

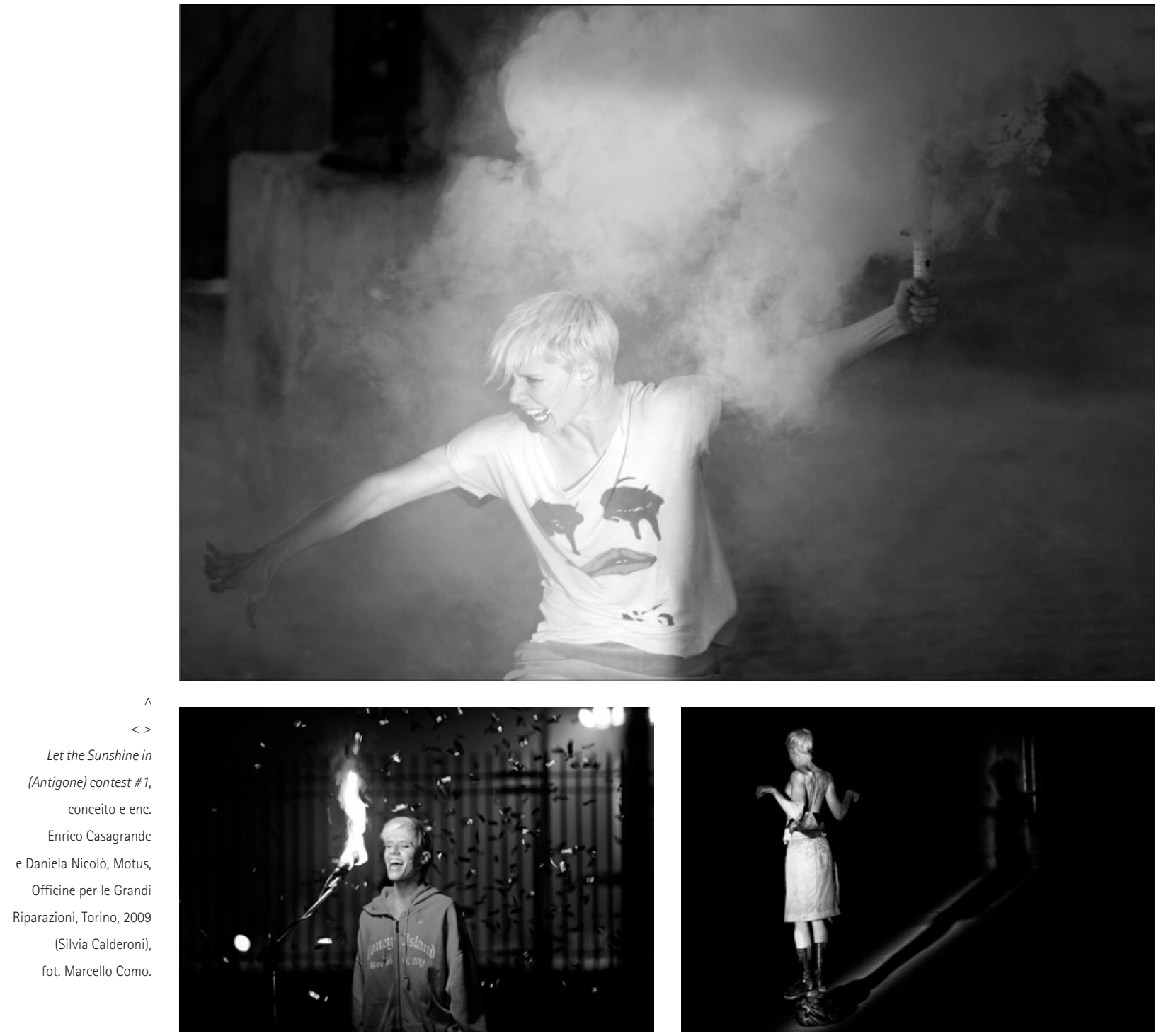

4. Motus: Let the Sunshine in (Antigone) contest \# 1. Tanto Anagoor empurrava para a beleza e equilibrio, quanto Motus atirava para a desolação e o desamparo. Não há nenhum juizo de valor nesta afirmação: trata-se duma simples constatação. Coerente com o seu percurso e opções estéticas, a companhia Motus (ex-Opere dell'Ingegno), criada em 1991 e sediada em Rimini, para além da performance dedica-se à produção de vídeo e instalações, experimentando constantes contaminações artísticas, resgatando do abandono espaços não convencionais, reinterpretando de modo subversivo textos e autores clássicos e/ou contemporâneos ilustres, mas também poetas, pensadores e cineastas, com os respectivos imaginários, e ainda misturando os elementos que compõem as suas intervenções performativas numa perspectiva pós-moderna, em que o fragmento, a apropriação de várias linguagens e modalidades de representação encontram a sua razão de ser, numa espécie de celebração, sem nenhuma pompa nem circunstância da capacidade de resistência e sobrevivência das artes, apesar da despromoção e massificação da cultura, e dos homens, e apesar também da precariedade e deterioração do quotidiano. Perante a falência das democracias aparentes que nos governam, na degradação das vidas que somos condenados a arrastar, neste tempo desnorteado e desprovido de referências colectivas, a Winnie beckettiana esforçar-se-ia por viver já não dias, mas apenas raros instantes felizes, duma felicidade outra resto entre restos. Vestígio duma tradição há muito sepultada, este espectáculo é o primeiro duma trilogia, trágica e actualizada, do mito como veículo residual para a interpelação do presente. Da Antigona sofocleana não restavam senão farrapos de texto e apontamentos dramatúrgicos; no lugar do Teatro de Dionísio da antiga Atenas, o inóspito Rossio de São Brás em Évora; em vez da cidade em peso para comungar do mito, uma ínfima minoria de espectadores, um coro modesto e mudo, dela representativa e disposta no meio do campo em terra batida, erguendo uma barreira que separava os dois actores ora figurando-se a si mesmos, ora desdobrando-se em Antígona / Isménia e Polinices / Etéocles. Biblicamente: nas nuvens de pó levantadas pelo vento, acabávamos por ser pó, no meio do pó. 0 sentimento de deriva perpassou todos os momentos do espectáculo, inclusive na reevocação do musical Hair (1967), um dos mitos da contracultura hippie dos anos Sessenta, mas em que o seu hino pacifista, Let the Sunshine in [Deixem o sol brilhar], apelo inserido no título e cantado aos berros, denunciava mais um 

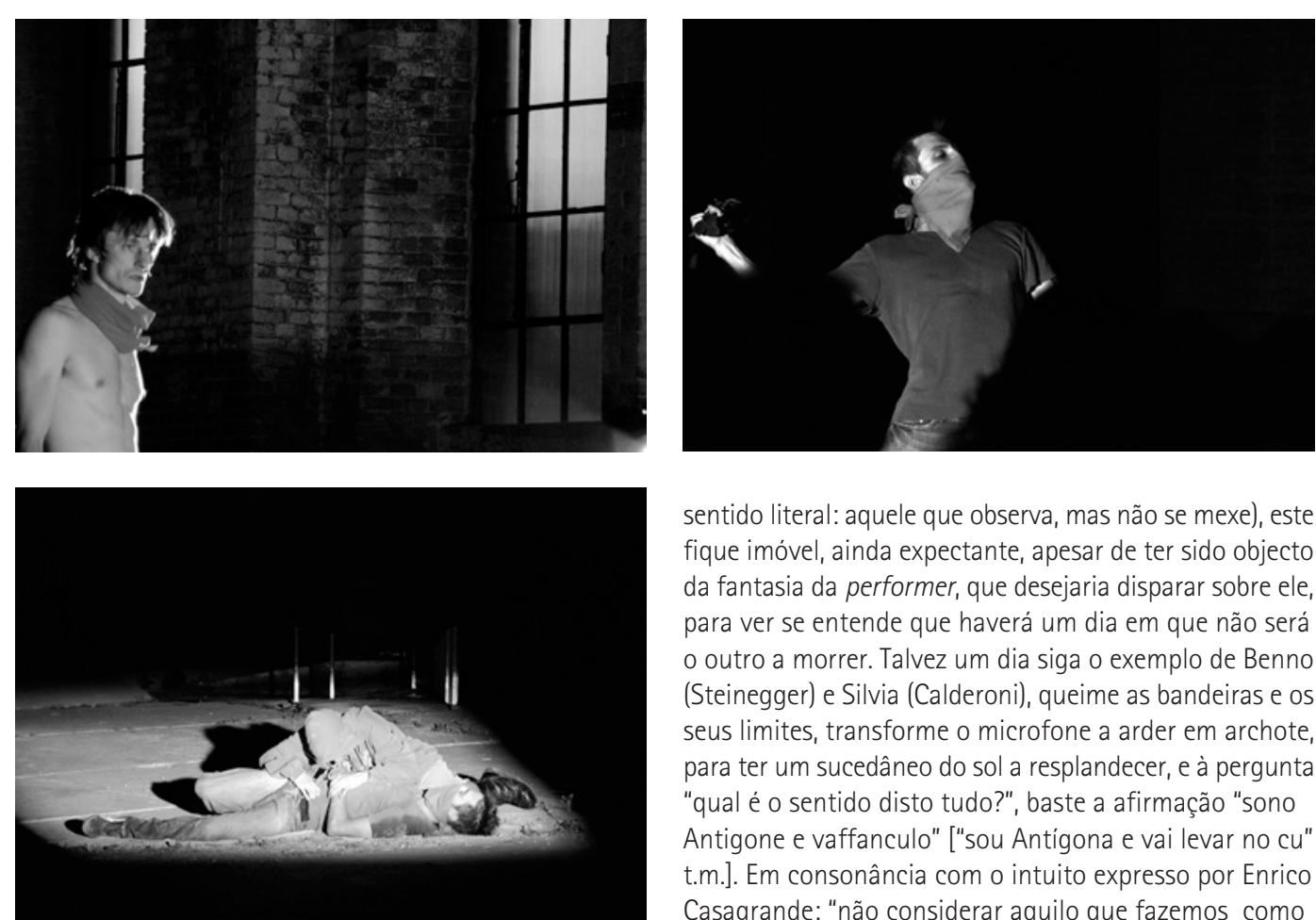

naufrágio da esperança num mundo melhor e dos laços fraternais duma humanidade esvaziada do humano. Filosófica e antropologicamente, a cultura e a epopeia do homem que deixa o seu estado animal começariam pela tomada de consciência da morte, que passou a ser ritualizada para fins de domesticação. Ora, nas sociedades actuais a morte é uma realidade interdita, submetida a processos de constante negação: a sociedade de consumo promove e idealiza o culto da beleza, riqueza e juventude, ocultando os seus opostos, desvalorizando e desprezando as vidas verdadeiras e os seus sentidos, pelo que a exploração e as guerras - praticadas para assegurar a afirmação daquelas mentiras - não passam de males menores e necessários. A incapacidade, ou impossibilidade, de esta nova Antígona comunicar com os seus irmãos, reflecte então o exilio da palavra, da ética e dos valores humanistas, que orientavam os seres e os poderes instituidos. Quantas "balas perdidas" acabam na carne dos inocentes, como aconteceu ao jovem Alexis Grigoropoulos, a quem esta performance foi dedicada, trazendo à cena a evocação do polícia que o matou, para defender o poder, esquecido do seu dever de proteger as pessoas? Quem nos defende de quem já não nos defende, sejam eles eleitos, paladinos a soldo dos eleitos ou eleitores esperançosos de beneficiar nem que seja das migalhas dos privilégios daqueles? Como travar a sua arrogância, os seus sentimentos de omnipotência e a sua certeza de impunidade? E como transformar, hoje, o dissentimento e a indignação em acção sem desistir? Como passar de Sófocles a Brecht? Nem que seja por intermédio de dois actores representando-se a si próprios, mas também duma Antígona que continua a transgredir a lei para honrar a fé, a obedecer aos laços de sangue naturais e a desrespeitar as leis do estado de que discorda, e um Polinices que na nudez em cena reencontra a sua casa, um eu sem superestruturas nem disfarces. Nem que ao pedir ajuda a um público anquilosado no seu papel de espectador (no seu sentido literal: aquele que observa, mas não se mexe), este fique imóvel, ainda expectante, apesar de ter sido objecto da fantasia da performer, que desejaria disparar sobre ele, para ver se entende que haverá um dia em que não será o outro a morrer. Talvez um dia siga o exemplo de Benno (Steinegger) e Silvia (Calderoni), queime as bandeiras e os seus limites, transforme o microfone a arder em archote, para ter um sucedâneo do sol a resplandecer, e à pergunta "qual é o sentido disto tudo?", baste a afirmação "sono Antigone e vaffanculo" ["sou Antígona e vai levar no cu" t.m.]. Em consonância com o intuito expresso por Enrico Casagrande: "não considerar aquilo que fazemos como um trabalho, mas como a vida" (apud Fratus 2002: 172, t.m.), Motus trouxe uma leitura desapiedada da insignificância e impotência cada vez maiores das nossas existências. Vale a pena visitar o seu sítio oficial $<$ www.motusonline.com> - com concepção, aspecto gráfico e fundo sonoro inesperados.

\section{Referências bibliográficas}

AA.W. (2004), "Os teatros que vêm da Itália" [número especial], Artistas Unidos: Revista, dir. Jorge Silva Melo, Lisboa, Livros Cotovia, n. 11 , Julho.

ALMEIDA, Maria João (2007), 0 teatro de Goldoni no Portugal de Setecentos, Lisboa, Imprensa Nacional-Casa da Moeda, Temas Portugueses.

ANAGOOR (2011), Com la virtù come guida e la fortuna per compagna, apresentação do espectáculo, texto policopiado.

DERAI, Simone (2011), correspondência electrónica, 17 de Outubro.

FANNYEtALEXANDER (2010), O/Z. Atlante di un viaggio / Atlas of a theatre journey, Milano, Ubulibri, I libri quadrati.

FERREIRA, José Alberto (2004), Estudos sobre Gil Vicente e a cultura teatral de Quinhentos, Coimbra, Angelus Novus, Estudos.

-- (org.) (2011), Escrita na paisagem. Festival de performance e artes da terra-2011, Jornal, Festival Escrita na paisagem.

FRATUS, Tiziano (a cura di) (2002), Lo spazio aperto. II teatro ad uso delle nuove generazioni, Roma, Editoria \& Spettacolo.

Sítios internet

$<$ www.anagoor.com>

$<$ www.fl.ul.pt/CETbase/default.htm>

$<$ www.escritanapaisagem.net>

$<$ www.fannyalexander.org/>

$<$ www.fmsoares.pt>

$<$ www.lenzrifrazioni.it/>

$<$ www.motusonline.com>

$<$ www.youtube.com/watch?v=E8UfggsVuvw>
$<>$

Let the Sunshine in

(Antigone) contest \#1, conceito e enc. Enrico Casagrande e Daniela Nicolò, Motus, Officine per le Grandi Riparazioni, Torino, 2009 k>Benno Steinegger; v Silvia Calderoni e Benno Steinegger), fot. END\&DNA. 